\title{
Implicit Biases a Breeding Ground for Stereotypes and Racism
}

\author{
Moore Y and Taylor $\mathrm{K}^{*}$ \\ Michigan Technological University, USA
}

*Corresponding author: Dr. Kamara Taylor, Michigan Technological University,

USA, Email: kamarataylor88@gmail.com

Research Article
Volume 3 Issue 5

Received Date: August 27, 2019

Published Date: September 13, 2019

DOI: $10.23880 /$ eoij-16000215

\section{Abstract}

This Manuscript examines stereotypes assigned by college students on different members of society. Specially through a quantitative research design, measured are stereotypes that exist amongst a small sample of Millikin University a Private University with a limited body of diverse students located in Decatur Il. The purpose of this survey was to examine the irrational stereotypes place on individuals when only a picture of their presumed race and gender are available.

Keywords: Stereotypes; Players; Behaviors; Millikin University

\section{Introduction}

As human beings, we unintentionally and automatically place other humans in categories such as, but not limited to: ugly, pretty, short, tall, fat or skinny. We see them as being different or being similar to us, this is called in-groups, or out-groups, those that we identify with and those that we don't. Universally we deem people in the out-group in a negative manner; we also make damaging assumptions without knowing them. "Impression formation in social psychology refers to the process by which individual pieces of information about another person are integrated to form a global impression of the individual (i.e. how one person perceives another person) [1]. This is why society can make broad assumptions about other people and explains how society can have these preconceived standards about a certain occupation or type of person. When given certain characteristics about an individual, society will assume stereotypes about that person, their occupation, their ethnicity, and certain behaviors.

Impression formation theories provide explanations for why this is. How are different members of society perceived by college students? I want to see what stereotypes college age individuals will place on a teacher, athlete and criminal. I will do this through selfadministered questionnaire only. The answer to this question will provide evidence on how different members of society are viewed, and how stereotypes affect how we see others. This research is also important because it contributes to social theories on stereotyping and can be used in practice. Making rash stereotypes and assumptions about someone can affect one's opportunities and can even be a life or death situation. The results of this study showed that African American males were more likely to be stereotyped as athletes more than anything else, and that women were stereotyped as educators more than anything else. However, since this study pool was only 50 the findings cannot be deemed significant.

\section{Review of Literature}

The first scholarly article that was examined was "White Men Can't Jump" it examined the perceptual confirmation of racial stereotypes concerning basketball players when information about the player's race and athleticism was available [2]. In this experiment it was concluded that the Black player was more aggressive, and his fouls were seen as rougher than the ones made by the White basketball player. This information is important because it shows that society sees Black people behaviors as more aggressive, even when they are the exact same as a White person. Not only were the Black players seen as more aggressive, there were also seen as more athletic 


\section{Ergonomics International Journal}

while the White player was perceived to have more basketball intelligence. This provides evidence that these stereotypes/ attributes have impacted the thoughts on athleticism, and aggression with Black and White basketball players that can also be applied to society [2]. Outside of sports Blacks are usually seen as more hostile and White people are seen as intellectual superiors.

The second journal article "Race-Crime Congruency in the Canadian Context" investigated "whether mock jurors would be biased against Black and Aboriginal Canadian defendants, and whether the effect of defendant race would depend on the type of crime with which the defendant was charged [3]. This is of importance because it highlights the stereotypes that Black people or more likely to commit violent crimes, and drug-related crimes, whereas white collar crimes are associated with White people [3]. This information shows that stereotypes have such an impact on society's views of people that they are willing to give longer sentences to someone who commits a crime that is stereotypically associated with their race.

"First, social-cognition research reveals that automatically activated stereotypes influence the perception of facial threat. Individuals holding hostile stereotypes toward dark-skinned out-group members perceive ambiguous dark-skinned faces as more hostile than similar light-skinned faces. Second, mediastereotyping research has found that the media can influence individuals' automatically activated stereotypes [4]. This quote comes from an article titled "Effects of News Stereotypes on the Perception of Facial Threat" this research is extremely important because it investigates the stereotypes that are showed through media and how that has impacted society's view of dark-skin individuals and why we interpret darker skin people to be more violent and hostile. "Perceptions of hostility may impact the perceiver's own behavior toward the interaction partner, but may also foster hostile reciprocation from the interaction partner [4]. This provides evidence to why Black individuals are seen as more violent and are deemed more likely to be criminals than non-Blacks.

\section{Methodology}

\section{Population and Sample}

The population was both males and females, and different nationalities but all were Millikin students, some were untraditional ages. The only requirements I had for my study pool was prior knowledge of the terms utilized (rapist, criminal, professor, teacher, golfer and athlete) and a Millikin University student. This was used as the requirements due to availability and access to participants in this age group, which indicated that they was aware of or was impacted by stereotypes. The pool of individuals sampled are the soon to be police officers, juries, and hiring managers. Their views on people can have either a positive or negative affect on the rest of someone's life [5,6].

\section{Measures}

The independent variable is the race of the individuals I ask about in my survey: a criminal, a teacher, a professor, an athlete, golfer, or rapist. The dependent variable is the college student's perception of these members of society: stereotypes and impression formation that relate to these individuals. A criminal will be conceptualized as "someone who has committed a crime, who has been be caught by authorities, found guilty of a blue collar crime and spent time in jail." A teacher will be conceptualized as "a professional educator who teaches primary students at a public school." And lastly, an athlete is conceptualized as "an individual that plays sports professionally and gets paid for it." All definitions are original.

\section{Procedures}

This study used only a self-administered questionnaire, distributed in Millikin University classrooms only. The questionnaire format was chosen to encourage transparency and automny in responses. This was also because I wanted honest, to ensure anonymous answers to this survey. A questionnaire was the most beneficial for this research and the least complex way to collect data. The study began by introducing of the Researcher, stating the purpose of the study (a questionnaire) is to study perceptions among college students, then stating the script (Appendix A), explaining that it will take less than 5 minutes. The Researcher explained that there are no rights or wrong answers and individual responses are completely confidential and anonymous, and that the participant's identity will never be associated with their responses. After that, the survey was distributed to each student who agreed to participate (no student chose to decline), instructing them to complete the survey, then the researcher collected the completed surveys and thank the respondents for participating.

\section{Questionnaire Design}

The questionnaire had photos of three black males professionally dressed and three white females 
professional dressed. The participants were asked to answer what each person was more likely to be. There were six options, criminal rapist, athlete, golfer, professor or teacher. There was also a space for participants to make comments. (Appendix A)

\section{Findings}

There was three hypotheses, the first one: H1: Educators will be stereotyped as female more than they will be males. The second one, H2: Athletes will be stereotyped as Black males more than White females and lastly H3: Criminals will be stereotyped as Black males more than White females. Hypothesis 1 was accepted, hypothesis 2 was accepted and hypothesis 3 was accepted. None of my hypotheses were rejected. In the charts below you will find the result for each person on the questionnaire. Participant's gender did not play a role in their answers. In Appendix A you will find what image corresponds with each graph.

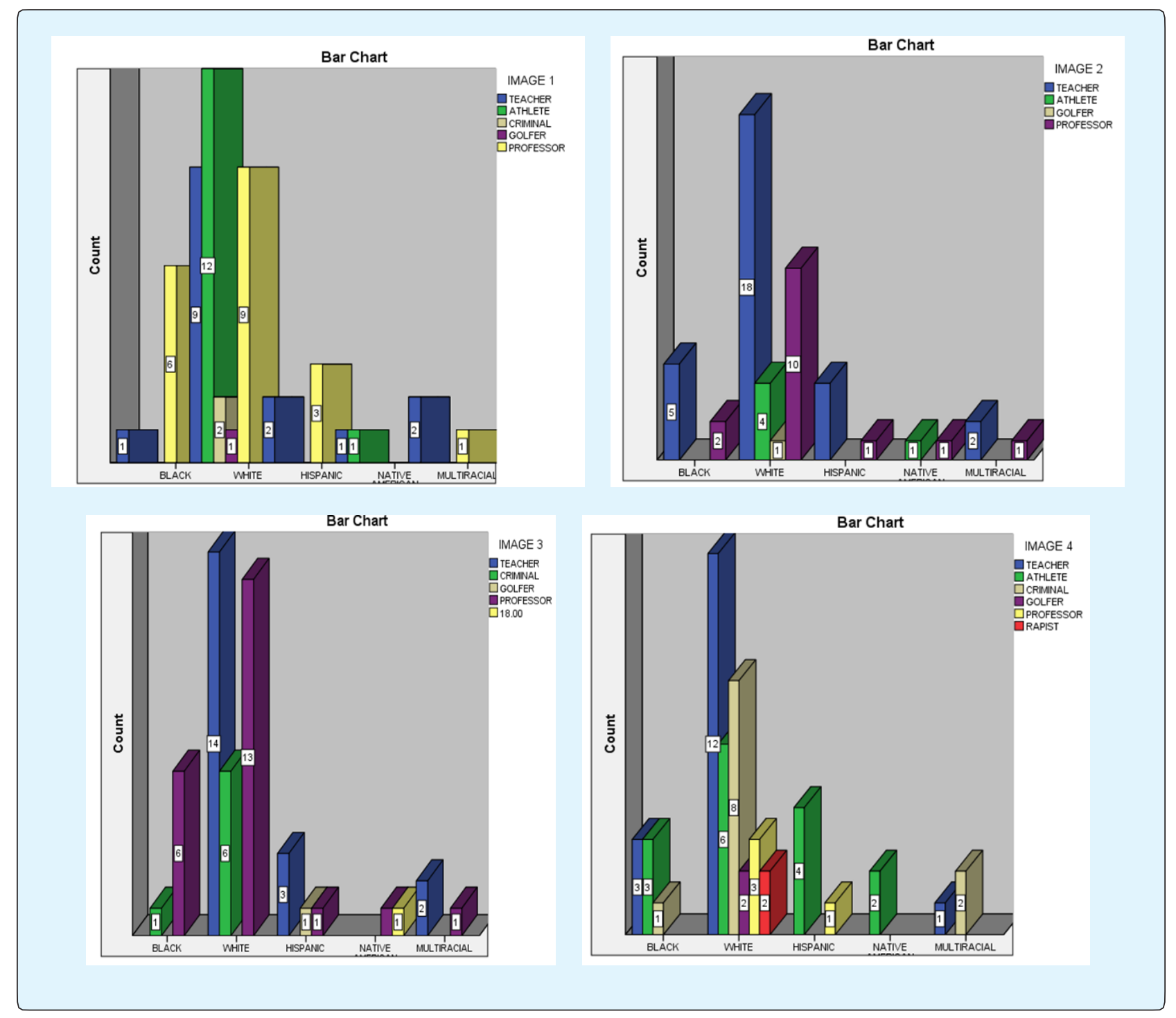

Moore Y and Taylor K. Implicit Biases a Breeding Ground for Stereotypes and Racism. 


\section{Ergonomics International Journal}

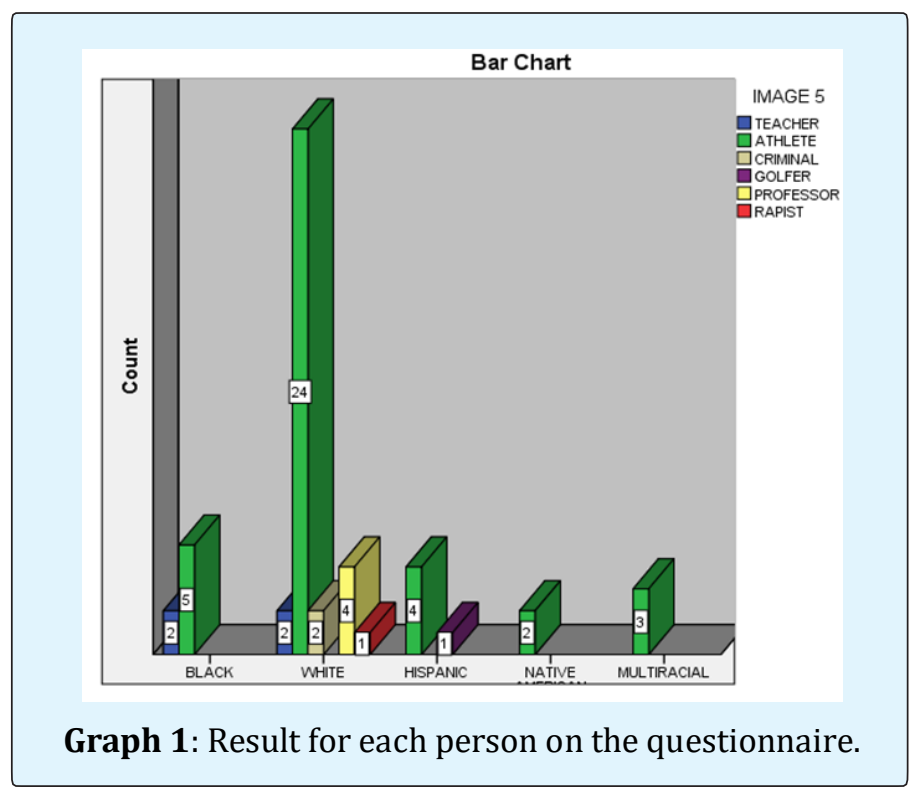

\section{Discussion}

There were only 50 participants therefore the sample size is a weakness in the study. However, even though the results are not significant they are leading toward confirming the initial hypotheses. Stereotyping is something humans cannot help, we place things in categories but the problem is that we place negative attributes on people, especially black males. This study agrees with prior studies because they both show that society views black men as more aggressive as and with less education than white individuals regardless of their sex. Even though this study pool did not think that black males were more likely to be criminals than athletes, they did see them to be more likely a criminal than white females. This is ironic seeming middle age white woman commit more crimes that middle-aged black men. Middle aged black men get followed in stores because workers believe they will steal when the increase rate of retail theft is committed statically higher by middle aged white woman in America.

This study identifies the gap but did not provide a way to help with this. Society must find ways to stereotype without having negative attributes about the out-group. Making rash stereotypes and assumptions about someone can affect one's opportunities and can even be a life or death situation. This research shows that in 2017, Blacks are still seen as less educated and more hostile than their white counter parts. Future research will provide participants with white male and black females in the questionnaire and ask the same question, The participant pool will also increase. This way broader conclusions on how society view race will be examined. Society has stereotypes and society automatically makes assumptions about people, the titles they hold or what attributes they should hold for certain occupations. This is a natural thing and is only negative and dangerous because stereotypes are biased and untrue and creates a breathing ground for discriminatory practices.

\section{References}

1. (2016) Impression Formation. The Free Encyclopedia.

2. Stone Jeff, Zachary W Perry, John M Darley (1997) White Men Can't Jump: Evidence for the Perceptual Confirmation of Racial Stereotypes Following a Basketball Game. Basic and Applied Social Psychology 19(3): 291-306.

3. Maeder Evelyn M, Susan Yamamoto, Laura A McManus (2016) Race-Crime Congruency in the Canadian Context. Canadian Journal of Behavioral Science 48(2): 162-170.

4. Arendt Florian, Nina Steindl, Peter Vitouch (2015) Effects of News Stereotypes on the Perception of Facial Threat. Journal of Media Psychology: Theories, Methods and Applications 27(2): 78-86.

5. Bavishi Anish, Juan M Madera, Michelle R Hebl (2010) The Effect of Professor Ethnicity and Gender on 


\section{Ergonomics International Journal}

Student Evaluations: Judged Before Met. Journal of Diversity in Higher Education 3(4): 245-256.

6. Glick Peter, Korin Wilk, Michele Perreault (1995)

Images of Occupations: Components of Gender and
Status in Occupational Stereotypes. Sex Roles 32(910): 565-582. 